\title{
Importance of clinical medicine in medical education: review of the articles in this issue
}

\author{
Oh Young Kwon
}

Department of Medical Education and Medical Humanities, Kyung Hee University School of Medicine, Seoul, Korea

\section{의학교육에서 임상의학의 중요성: 이번 호에 게재된 연구에 대한 검토}

경희대학교 의학전문대학원 의학교육 및 의인문학교실

\section{권오영}

우리나라 의과대학/의학전문대학원의 교육 목표는 일차 진료의사의 양성이다. 이 목표 달성을 위해 각 대학의 졸업성 과에는 학생들의 '임상수행능력의 향상'이 항상 포함되어 있 다. 임상의학 교육과정은 임상 이전에 배우는 많은 과목을 밑 거름 삼아 올바르게 진료하고 치료할 수 있는 의사를 만드는 데 반드시 필요하다. 이러한 관점에서 임상의학 교육은 훌륭 한 임상수행능력을 갖춘 일차 진료의의 배출이라는 최종 결 실을 맺는데 가장 중요한 과정이며, 올바른 임상의학의 교육 은 대부분의 시간을 환자 진료에 매진해야 하는 의사 생활 중 가장 중요한 부분이 아닐까 한다. 위의 대명제 달성뿐만 아니 라 임상의학의 교육의 중요성이 강조된 계기는 의사국가시험 에서 실기시험의 도입이라 할 수 있다. 의사국가시험의 합격 이라는 목표를 위해 각 대학들은 임상교육을 더욱 강조하고 있다. 의과대학생 모두가 졸업 후 임상의사의 길을 택하지는 않지만, 대부분은 임상의사가 되기를 꿈꾸며 열심히 노력하 고 있다. 이러한 임상의학 교육의 중요성을 잘 반영하듯 우리
학회지의 최근의 연구에서 임상의학에 관한 연구 논문이 증 가하고 있음을 알 수 있다. 이번 호에도 임상의학을 주제로 한 몇 가지의 연구들이 게재되었다.

4 학년 학생들을 대상으로 한 임상진료시험 성적의 예측요 인을 분석한 연구[1]는 임상수행능력의 결정 요인을 분석하 기 위해 임상진료시험 성적과 기존 성적을 비교 분석한 연구 이다. 학생들의 기존 성적을 인지 영역과 행동 영역 등으로 분 류하여 분석한 결과, 기존 성적 중 인지 영역보다는 행동 영역 점수가 임상수행능력과 연관성이 있다고 보고하였다. 임상능 력 배양을 위해 각 대학에서는 강의와 지필시험 등의 인지 영 역의 교육보다는 실습 영역의 교육에 대한 노력의 필요성을 강조한 연구라 할 수 있겠다. 또 다른 임상교육에 관한 연구로 한국의과대학. 의학전문대학원협회에서 개발한 진료수행과 기본임상술기 지침 개발에 대한 사례 보고[2]가 게재되었다. 이 지침은 2010년 3월에 처음으로 개발되어 학생들의 임상능 력 강화에 큰 밑거름이 되어 왔다. 2016년에 개정될 이 지침
Received: November 16, 2015 • Revised: November 16, 2015 • Accepted: November 16, 2015 Corresponding Author: Oh Young Kwon (http://orcid.org/0000-0003-0817-2256) Department of Medical Education and Medical Humanities, Kyung Hee University School of Medicine, 26 Kyungheedae-ro, Dongdaemun-gu, Seoul 02447, Korea Tel: +82.2.961.9102 Fax:+82.2.969.6958 email: koy0004@hotmail.com
Korean J Med Educ 2015 Dec; 27(4): 243-245. http://dx.doi.org/10.3946/kjme.2015.27.4.243 eISSN: 2005-7288

(C) The Korean Society of Medical Education. All rights reserved. This is an open-access article distributed under the terms of the Creative Commons Attribution Non-Commercial License (http:// creativecommons.org/licenses/by-nc/3.0/), which permits unrestricted non-commercial use, distribution, and reproduction in any medium, provided the original work is properly cited. 
의 개발 과정을 상세하게 기술함과 동시에 새롭게 개정된 지 침의 방향과 내용을 일목요연하게 정리하여 발표하여, 임상 교육을 담당하게 될 교수들이 보다 쉽고 정확한 교육을 하는 데 큰 도움을 줄 수 있을 것이다. 임상실습과정에서 포트폴리 오 개발 사례[3]도 임상교육 담당자들의 관심을 충분히 끌 수 있는 좋은 사례 연구이다. 포트폴리오 교육을 아직 도입하지 않은 학교에서는 시행 방법과 세부 운영에 대한 지침이 필요 했을 것이며, 교육 및 평가도구로 포트폴리오를 이미 도입한 학교에서도 타 학교의 운영 경험이 도움이 될 것이다. 이 연구 에서는 포트폴리오 개발에 대한 상세한 보고를 함으로써 포 트폴리오를 준비하는 학교뿐만 아니라 시행에 어려움이 있는 학교의 담당자에게 좋은 지침이 될 수 있을 것이다. 새로운 장 비를 임상교육에 이용한 논문도 인상적이다. 비디오 후두경 을 통한 기관 내 삽관의 교육 적합성 연구[4]는 앞으로 임상교 육에 도입 가능성이 있는 장비를 학생들 교육에 이용한 연구 라는 점이 유용하고 가치가 있다.

이번 호에서 주목할 만한 다른 주제는 2015년부터 시행되 고 있는 의예과 학제 도입에 따른 새로운 교육체제에 대한 연 구이다. 많은 수의 의과대학이 2005년부터 과거 6년제의 교 육과정에서 ‘ $4+4$ ' 학제인 의학전문대학원 체제를 도입하여 운 영하여 왔다. 의학전문대학원 체제로의 전환 당시 교수를 비 롯하여 학생들 또한 혼란이 있었으나 시간이 지남에 따라 차 차 안정화되었다. 그러나 대부분의 대학이 2015년부터 이전 체제인 의예과 2년, 의학과 4년의 학제로 회귀함에 따라 새로 운 학제에 대한 우려가 적지 않았다. 과거부터 의예과 교육과 정에 대한 통일된 기준이 평가인증제도의 일부 기준을 제외 하고는 존재하지 않았던 것도 걸림돌이었다. 표준화된 의예 과 교육과정이 필요한 시점에서 이번 호에 실린 의예과 교육 과정 평가 준거 개발 연구[5]는 새로 도입되는 의예과 교육의 질 관리 및 향상에 기여할 수 있는 아주 시기적절한 연구라 하겠다. 다양한 문헌연구와 전문가 협의를 통해 평가 근거를 마련하였고 다양한 의학교육 분야 종사자들을 패널로 구성하 여 델파이 조사를 시행하여 우리나라 실정에 맞는 기초의과 학 지식의 습득과 인성 함양을 강조한 의예과 교육과정 평가 의 준거를 제시하였다. 2015년 6년제를 도입한 의과대학뿐만 아니라 향후 의과대학으로의 전환을 모색하는 대학에서도 좋 은 자료로 활용할 수 있을 것이다. 다양한 다른 주제의 연구도
눈여겨볼만하다. 의과대학생의 번아웃 유병률과 관련 요인에 관한 연구[6]에서 성별, 저조한 성적, 유급에 대한 걱정, 불편 한 시설, 그리고 우울 증상 등이 관련이 있는 것으로 나타났 다. 많은 스트레스를 받는 의과대학생의 고충을 덜어주기 위 해 의학교육자들이 한번쯤 진지하게 고민해 보아야 할 주제 이다.

의료기술이 발전함에 따라 의학의 범위는 자연스럽게 넓어 지고 있으며, 의학교육 또한 그에 맞추어 지속적으로 그 범위 를 넓혀가고 있다. 여러 교육자들의 노력으로 우리나라의 의 학교육은 꾸준하게 발전하고 있으며, 의학의 빠른 변화에 잘 대처하고 있다. 이론 중심에서 실제적인 교육을 중요시하는 방향으로 나아가고 있고, 교육방법 또한 다양해지고 있다. 이 러한 흐름에 맞추어 우리 학회지에 꾸준하게 좋은 연구 결과 들이 게재되고 있다. 이번 호에 게재된 다양한 분야의 연구 결 과들은 의학교육자들이 실제 교육현장에서 쉽고 유용하게 적 용할 수 있을 것이며, 그 교육적인 가치 또한 높다고 할 수 있 겠다.

Acknowledgements: None.

Funding: None.

Conflicts of interest: None.

\section{REFERENCES}

1. Park KY, Park HK, Kim JH, Hwang HS. Predictors of clinical practice examination scores of fourth year medical students after core clinical clerkships. Korean J Med Educ 2015; 27: 275-282.

2. Roh HR, Lee KM, Eo E, Hong YS, Lee H, Jang BW, Rhee BD. Development of guide to clinical performance and basic clinical skills for medical students. Korean J Med Educ 2015; 27: 309-319.

3. Roh HR, Lee JT, Yoon YS, Rhee BD. Development of a portfolio for competency-based assessment in a clinical clerkship curriculum. Korean J Med Educ 2015; 27: 
32I-327.

4. Choo HJ, Kwon OY, Ko YG. Educational suitability of endotracheal intubation using a video-laryngoscope. Korean J Med Educ 2015; 27: 267-274.

5. Hwang J, Shin JS, Yoon HB, Kim DH, Yoo DM, Kim EJ, Lee SH. Research and development of evaluation criteria for premedical curriculum. Korean J Med Educ 2015; 27: 255-265.

6. Choi J, Son SL, Kim SH, Kim H, Hong JY, Lee MS. The prevalence of burnout and the related factors among some medical students in Korea. Korean J Med Educ 2015; 27: 301-308. 